\title{
The Evolution of the Labor Market for Medical Interns and Residents: A Case Study in Game Theory
}

\section{Citation}

Roth, A.E.. 1984. The Evolution of the Labor Market for Medical Interns and Residents: A Case Study in Game Theory. Journal of Political Economy 92: 991-1016.

\section{Permanent link}

http://nrs.harvard.edu/urn-3:HUL.InstRepos:29410143

\section{Terms of Use}

This article was downloaded from Harvard University's DASH repository, and is made available under the terms and conditions applicable to Other Posted Material, as set forth at http:// nrs.harvard.edu/urn-3:HUL.InstRepos:dash.current.terms-of-use\#LAA

\section{Share Your Story}

The Harvard community has made this article openly available.

Please share how this access benefits you. Submit a story.

\section{Accessibility}




\title{
The Evolution of the Labor Market for Medical Interns and Residents: A Case Study in Game Theory
}

\section{Alvin E. Roth}

University of Pittsburgh

\begin{abstract}
The organization of the labor market for medical interns and residents underwent a number of changes before taking its present form in 1951. The record of these changes and the problems that prompted them provides an unusual opportunity to study the forces at work in markets of this kind. The present paper begins with a brief history and then presents a game-theoretic analysis to explain the orderly operation and longevity of the current market, in contrast to the turmoil that characterized various earlier short-lived attempts to organize the market. An analysis is also given of some contemporary problems facing the market. A subsidiary theme of the paper concerns the history of ideas: the problems encountered in the organization of this market, and some of the solutions arrived at, anticipated the discussion of such issues in the literature of economics and game theory.
\end{abstract}

\section{Introduction}

This paper concerns the labor market for medical interns and residents and how it has evolved from the beginning of the century to the present time. The paper will discuss briefly the history of the various

I have profited from conversations and correspondence on this topic with David Gale, Gene Gruver, and John S. Graettinger, M.D., as well as from the comments of participants at seminars where $\mathbf{I}$ have presented parts of this work over the last 4 years, at Buffalo, Yale, Harvard, Northwestern, University of Pennsylvania, Virginia Polytechnic Institute, Stanford, Minnesota, and Chicago. This work has been supported by grants from the National Science Foundation and the Office of Naval Research and by fellowships from the John Simon Guggenheim Memorial Foundation and the Alfred P. Sloan Foundation.

[Joumal of Political Economy, 1984, vol. Y2. no 6

C) 1984 by The University of Chicago. All rights reserved. 0022-3808/84/9206-0002\$01.50 
institutional procedures by which this market has been implemented and present a formal theoretical analysis of what these procedures accomplished and the problems they encountered.

From the turn of the century until 1945, the market suffered from a Prisoner's Dilemma problem in which competition by hospitals for interns manifested itself in a race to sign employment contracts earlier and earlier in a medical student's career. This problem was successfully resolved in 1945, but the market then suffered for several years from a "recontracting problem," in which the market's failure to implement an outcome in the core made it difficult for the market to clear. This recontracting problem was closely related to an "incentive problem" that put a premium on strategic behavior by market participants, which manifested itself most clearly when a centralized market mechanism was introduced in 1950. All of these problems were apparently resolved, at least in large part, by the adoption of a different centralized market mechanism in 1951 , which remains in use to this day.

It will be shown that this mechanism implements an outcome in the core of the market, and some of its other properties will be studied. Some modern problems this market mechanism has encountered and the theoretical issues they raise will also be considered. One of the most interesting of these concerns the transformation of the market into one containing dual-career households, as increasing numbers of medical school graduates are married to one another and need to be employed in nearby locations. It will be shown that no core outcomes need exist in such markets.

A subsidiary theme explored in this paper concerns the history of ideas. It will be noted that the practical problems encountered by the medical profession in the organization of this labor market, and some of the solutions proposed, anticipate by $a$ number of years the discussion of similar issues in the literature of economics and game theory.

Section II briefly discusses the history of the market, and Section III presents an analysis. Section IV analyzes some current problems facing the market. All proofs are presented in Sections V and VI, and Section VII concludes.

\section{Some Institutional History}

The internship was first introduced around the turn of the century as an optional form of postgraduate medical education. For students, internships offered a concentrated exposure to clinical medicine, and for hospitals they offered a supply of relatively cheap labor. The number of positions offered for interns was, from the beginning, greater than the number of graduating medical students applying for 
such positions,' and there was considerable competition among hospitals for interns.

One form in which this competition manifested itself was that hospitals attempted to set the date at which they would finalize binding agreements with interns a little earlier than their principal competitors. As a result, the date by which most internships had been finalized began to creep forward from the end of the senior year of medical school. This was regarded as costly and inefficient both by the hospitals, who had to appoint interns without knowing their final grades or class standings, and by the students and medical schools, who found that much of the senior year was disrupted by the process of seeking desirable appointments. Many resolutions were passed and much moral suasion was applied in efforts to remedy this state of affairs. A good idea of the situation in 1926 is conveyed in a letter to the Association of American Medical Colleges (Darrach 1927), the body of which is quoted in full:

For a number of years attempts have been made to defer the appointment of hospital internes until towards the close of the fourth year. The Association of American Medical Colleges, the Council on Medical Education of the American Medical Association, and the American Hospital Association have all passed resolutions favoring this idea. The difficulty has been in persuading someone to take the lead.

This is to inform you that it has been decided to defer the appointments of internes at the Presbyterian Hospital in the City of New York until some time in A pril.

It is earnestly hoped that other hospitals and schools will be able to act in a similar manner.

The advancement of the date of appointment was not halted, much less reversed, by these appeals and resolutions. A dozen years later, in an article devoted to the problem, Fitz (1939, p. 103) referred to Darrach's letter and added that "for some unknown reason the Presbyterian Hospital soon abandoned its stand . . .." He reported the results of a survey indicating that, in 1939, the bulk of intern appointments would be made during the Christmas holidays of the senior year, and many would be made earlier. He proposed that the problem could be solved if medical schools in the Association of American Medical Colleges (AAMC) would undertake not to give out before

\footnotetext{
1 The number of positions offered for first-year medical graduates exceeded the number of eligible applicants until the mid-1970s, at which time the total of U.S. medical school graduates plus foreign graduates exceeded the number of first-year positions. However, the number of positions offered continues to exceed the number of U.S. medical school graduates (see Graettinger 1976).
} 
some agreed date any information to hospitals regarding students' abilities. This suggestion was not adopted, however.

The advancement of the date of appointment continued at an accelerating pace, and in an address to the AAMC on the problem in 1944, Turner (1945, p. 27) reported that the standard appointment date "has now been advanced on the school calendar to the beginning of the junior year and, indeed, inquiries now come to me even from sophomores" (emphasis added). Thus in 1944 the date of appointment had advanced to 2 full years before the internship was actually to begin.

Turner proposed a number of steps to remedy this increasingly intolerable state of affairs. Most important, he again proposed that no information about medical students should be released by medical schools before some fixed date to be agreed upon. This proposal was adopted by the AAMC in consultation with the various hospital associations, and it was decided that neither scholastic transcripts nor letters of reference would be released prior to the end of the junior year for students seeking internships commencing in 1946.

This proved to be an effective remedy for the problem it was intended to solve. Appointments for 1946 internships were largely made in the summer of 1945, and in subsequent years the dates at which information was released by medical schools was moved later into the senior year, and the date at which appointments were made followed in step. However, a new problem appeared and manifested itself in the waiting period between the time offers of internships were first made and the time students were required to accept them.

The problem was that a student who was offered an internship at, say, his third-choice hospital, and who was informed he was an alternate (i.e., on a waiting list) at his second-choice hospital, would be inclined to wait as long as possible before accepting the position he had been offered, in the hope of eventually being offered a preferable position. Students who were pressured into accepting offers before their alternate status was resolved were unhappy if they were ultimately offered a preferable position, and hospitals whose candidates waited until the last minute to reject them were unhappy if their preferred alternate candidates had in the meantime al ready accepted positions. Hospitals were unhappier still when a candidate who had indicated acceptance subsequently failed to fulfil his commitment after receiving a preferable offer. In response to pressure originating chiefly from the hospitals, a series of small procedural adjustments were made in the years 1945-51. The nature of these adjustments, described next, makes clear how these problems were perceived by the parties involved.

For 1945, it was resolved that hospitals should allow students 10 
days after an offer had been made to consider whether to accept or reject it." For 1946," it was resolved that there should be a uniform appointment date (July 1) on which offers should be tendered (transcripts having been released on June 1 ) and that acceptance or rejection should not be required before July $8 .{ }^{4}$ By 1949 , the AAMC proposed ("Uniform Intern Placement Plan" 1949) that appointments should be made by telegram at 12:01 A.M., N ovember 15, with applicants not required to accept or reject them until 12:00 noon the same day. Even this 12-hour waiting period was rejected by the American Hospital Association (AHA) as too long: the joint resolution ("A ppointment of Interns" 1949) finally agreed on contained the phrase "no specified waiting period after 12:01 A.m. is obligatory" and specifically noted that telegrams could be filed in advance for delivery precisely at 12:01 A.M. In 1950, the resolution again included a 12hour period for consideration, with the specific injunction that "hospitals and/ or students shall not follow telegrams of offers of appointment with telephone calls" until the end of this period. ${ }^{5}$

By this time it was widely recognized both that there were serious problems in the last stage of the matching process and that these problems could not adequately be resolved by compressing this last stage into a shorter and shorter time period. In order to avoid these problems and the costs they imposed, it was proposed, and ultimately agreed, that a more centralized matching procedure should be tried (Mullin 1950; Mullin and Stalnaker 1951). Under this procedure, students and hospitals would continue to make contact and exchange information as before." (It is worth noting in this regard that the complete job description offered by a hospital program in a given year was customarily specified in advance; see, e.g., Stal naker [ 1953]. Thus the responsibilities, salary, etc., associated with a given intern-

\footnotetext{
* Unless otherwise stated, the resolutions discussed below are joint resolutions of the AAMC and the American Hospital Association (AHA). These resolutions were not legally binding on the member hospitals or on graduating students. For the first, see "Agreement on Internship Placement" (1945).

3 See "Report of the Committee on Internships" (1946). Of the previous year's resolution it is noted that "while not observed completely by a few medical schools and hospitals, [it] had been followed by most of the institutions in the country and had resulted in a very great advance in bringing order out of a chaotic situation."

4 "it was reported by a representative of the American Hospital Association that violations by hospitals was as high as 25 percent: nevertheless the American Hospital Association wants the system to be continued" ("Internships" 1947, p. 46).

5 "Modifications of Cooperative Plan for Appointment of Interns" (1950). Note that the injunction against telephone calls was two way, in order to stem a flood of calls both from hospitals seeking to pressure students into an immediate decision and from students seeking to convert their alternate status into a firm offer.

6 That is, the application and interviewing process would remain unchanged. (At this time Mullin[1950] states there were about 9,300 internships being offered, to about 6,000 medical school graduates.)
} 
ship, while they might be adjusted from year to year in response to a hospital's experience in the previous year's market, were not a subject of negotiation with individual candidates.) Students would then rank in order of preference the hospital programs to which they had applied, hospitals would similarly rank their applicants, and all parties would submit these rankings to a central bureau, which would use this information to arrange a matching of students to hospitals and inform the parties of the result. ${ }^{7} \mathrm{~A}$ specific algorithm was proposed to produce a matching from the submitted rankings, and this will be discussed in the next section.

It was agreed to try the proposed procedure in a trial run for the 1950-5 1 market, which would not be used actually to match students and hospitals in that year. Instead, participants were asked to submit rankings as if they would be used for determining the final matching, and the plan would be evaluated for actual use after the trial run had occurred. On the basis of the trial run, the relevant medical associations agreed to adopt the procedure for the 1951-52 market. The procedure was to be voluntary: students and hospitals were both free either to participate in the process or to seek internship appointments on their own.

After the procedure was announced but before it was implemented, objections by student representatives were raised to the algorithm used to produce a matching from the rankings submitted. Specifically, they observed that this algorithm made it a matter of great importance how adroitly a student composed his rank-order list. A student might suffer if he took a "flyer" and gave high rank to hospitals he preferred but had little chance of being matched with ("The Internship Matching Plan" 1952). That is, it was noted that a student who submitted a rank order of hospitals corresponding to his true preferences might receive a less preferable match than if he had submitted a different rank order. In response to these objections, a new algorithm was substituted for the old in the 1951-52 matching plan (Mullin and Stalnaker 1952). This substitution was judged to be of sufficiently small import that its details were not widely disseminated, the announcements concerning the plan having already been distributed before the substitution was made.

In what follows, the initial algorithm will be called the "trial-run

\footnotetext{
7 Under the procedure being discussed here, hospitals actually tanked students in groups, rather than in a strict rank order, although in the procedure discussed next, hospitals as well as students submitted strict rank orders. Surveys of medical students (see, e.g., Rutkow and Glasgow 1978) suggest that the most important factors determining student preferences over hospital programs have to do with their reputation as educational programs, less importance being assigned to factors such as on-call schedule, patient population, and salary.
} 
algorithm," and the algorithm that replaced it will be called the "NIMP algorithm," for National Intern Matching Program, the name adopted for this plan in 1953. The matching plan using the NIMP algorithm remains in use to this day, although the market that it serves has undergone considerable change in the intervening years. ${ }^{8}$ This longevity and the very high levels of (voluntary) participation the system has attracted are particularly surprising in view of the turmoil in this market in the years immediately prior to the establishment of the NIMP. ${ }^{9}$ Much of the theoretical analysis in the following section is intended to shed light on the causes of this success.

\section{Theoretical A nalysis}

The reasons for continually advancing the date at which interns were appointed before 1945 are well understood, and little need be said about them here. Although hospitals all preferred as late an appointment date as possible, each preferred to appoint its interns earlier than its competitors: the situation is well modeled as a multiple-agent Prisoner's Dilemma. However, the negative externality produced by this competitive behavior on the part of hospitals was also experienced by the medical schools, which had no corresponding incentive to advance the appointment date. Consequently, once medical schools collectively imposed a date before which they would not release the information about students needed to make appointments, a new equilibrium was created at which there was no tendency for the date to advance."

${ }^{8}$ In 1968 the National Intern Matching Program (NIMP) was renamed the National Intern and Resident Matching Program (NIRMP), and in 1978 renamed the National Resident Matching Program (NRMP), to reflect changes in the structure of postgraduate medical training.

$\mathbf{9}$ In the first years, over 95 percent of eligible students and hospitals participated in the system (cf. Mullin and Stalnaker 1952.) These high rates of participation continued until the early 1970s (see Checker 1973), after which there was some decline, for reasons that will be discussed later.

10 The importance of the medical schools' acting collectively in this regard was emphasized in Curran (1945, p. 37) as follows: "While the Executive Council has already recommended that no letters of recommendation supporting internship applications should go out until after the end of the junior year, Dr. Turner's insistence that this be agreed on by all the medical schools is worthy of emphasis, Its importance may be illustrated by a situation created one year ago among the schools in New York City by such an agreement on a local basis. It was then discovered that in two neighboring cities all internship vacancies were being filled by students before the end of the third year. As a result, the New York schools were forced to abrogate hastily their rule against sending out earlier information." 


\section{A. Stability}

To analyze the market after 1945 , it will be helpful to consider it as a game whose players are a set $H=\left\{h_{1}, \ldots, h_{m}\right\}$ of hospital programs offering positions to first-year graduates, and a set $S=\left\{s_{1}, \ldots, s_{n}\right\}$ of graduating students. Each hospital program $h_{i}$ has some number $q_{2}$ of' identical first-year positions it is seeking to fill, and each student is seeking one position." The rules of the game are that any student may fill any position if and only if both the student and the hospital agree, that is, if and only if the position is proferred by the hospital and accepted by the student. Each student has preferences over all the hospital programs he is willing to accept, and each hospital program similarly has preferences over all the students it is willing to accept. ${ }^{12}$ An agent who is not indifferent between any two acceptable alternatives (so that his preferences constitute a rank ordering) will be said to have strict preferences. An outcome of the game is an assignment of students to hospital programs, with no more than $q_{i}$ students being assigned to any program $h_{i}$. A given outcome $x$ is called unstable if some student or hospital receives an unacceptable assignment or if there exists a hospital program $h_{i}$ and student $s_{j}$ who each prefer the other to their assignment at $x$.

Formally, for each hospital program $h_{i}$, let $s_{j} P\left(h_{i}\right) s_{k}$ denote that $h_{i}$ prefers students, to student $s_{k}$, let $s_{j} I\left(h_{i}\right) s_{k}$ denote that $h_{i}$ is indifferent between the two, let $s_{i} P\left(h_{i}\right) u$ denote that $h_{i}$ prefers filling a position

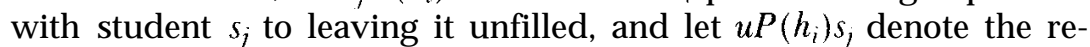
verse. Then each $h$, has preferences defined over its set $\left\{s_{j} \in\right.$ $\left.S \mid s_{j} P\left(h_{i}\right) u\right\}$ of acceptable students. Similarly, each student $s_{j}$ has preferences defined over his set $\left\{h_{i} \in H \mid h_{i} P\left(s_{j}\right) u\right\}$ of acceptable hospital programs. ${ }^{13}$ An outcome is represented by a function $\mathrm{x}: S \rightarrow H \mathrm{U}\{\mathrm{u}\}$, with $\left|\left\{s_{i} \mid x_{i}\left(s_{i}\right)=h_{i}\right\}\right| \leqslant q_{i}{ }^{14}$ For any $s_{j}$ in $S, x\left(s_{j}\right)=h_{i}$ denotes that $s_{j}$ is

\footnotetext{
1 A hospital typically offers a number of different kinds of positions, but these are separated into different programs, each administered separately.

12 Students may regard some hospital programs as unacceptable and hospitals may so regard some students, in the sense that it would be preferable to defer taking or offering any appointment rather than one that is unacceptable. For example, students and hospitals who have not exchanged the necessary preliminary information (e.g., transcripts and interviews) may be expected to regard one another as unacceptable (at least for the time being). Since interviews are time consuming, students face a problem in deciding what hospitals to apply to, and hospitals face a similar problem in deciding whom to invite for interviews, but these problems will not be addressed here.

${ }^{13} \mathrm{We}$ will not need to be concerned over what an agent's preferences may be over those alternatives that are unacceptable. However, the formal description of the game given here is incomplete in another respect as well, since the preferences of hospitals for groups of students have not been specified (see Roth 19846). The description given here will nevertheless be complete enough for the purposes of this paper.

${ }^{14}$ For any set $T,|T|$ denotes the number of elements in $T$, so, e.g., $\left\{\left\{s_{i} \mid x\left(s_{i}\right)=h_{i}\right\} \mid\right.$ is the number of students employed by $h$, at the outcome $x$.
} 
assigned a position in hospital program $h_{i}$, and $x\left(s_{j}\right)=u$ denotes that $s_{j}$ is unassigned. For any $h_{i}$ in $H$ let $x\left(h_{i}\right)=\left\{j_{j}\right.$ in $\left.S \mid x\left(s_{j}\right)=h_{i}\right\}$ be the set of students assigned to $h_{i}$, it being understood that if $\left|x\left(h_{i}\right)\right|<q_{\text {, then }} q_{i}-$ $\left|x\left(h_{i}\right)\right|$ positions are unfilled in program $h_{i}$. An outcome $x$ is unstable if for some student $s_{j}, u P\left(s_{j}\right) x\left(s_{j}\right)$; or if for some hospital program $h_{i}$, $u P\left(h_{i}\right) s_{j}$ for some $s_{j}$ in $x(h$,$) ; or if there exists a hospital program h_{i}$ and student $s_{j}$ such that both (i) $h_{i} P\left(s_{j}\right) x\left(s_{j}\right)$ and (ii) $s_{j} P\left(h_{i}\right) \sigma$ for $\sigma$ in $x\left(h_{i}\right)$ if $\left|x\left(h_{i}\right)\right|=q_{i}$ or $\sigma$ in $x\left(h_{i}\right)$ U $\{u\}$ if $\left|x\left(h_{i}\right)\right|<q_{i}$.

Thus an outcome is unstable if it gives some student or hospital program an unacceptable (not individually rational) assignment or if there exists a students, and hospital program $h_{i}$ such that (i) $s_{1}$ prefers $h_{i}$ to the hospital $x\left(s_{j}\right)$ and (ii) $h_{i}$ prefers $s_{j}$ to the incumbent in one of its $q_{i}$ available positions. When no confusion will result, a hospital program will henceforth sometimes be referred to simply as a hospital.

An outcome that is not unstable in this sense is called stable, and it is straightforward to verify that the set of stable outcomes is the core defined by weak domination of this game. ${ }^{15}$ Denote the set of stable outcomes by $\mathrm{C}(\mathrm{P})$, where $\mathrm{P}$ is the $(m+\mathrm{n})$-tuple of agent preferences; that is, $\mathbf{P}=\left[\mathbf{P}\left(h_{1}\right), \ldots, \mathbf{P}\left(h_{m}\right), \mathbf{P}\left(s_{1}\right), \ldots, \mathbf{P}\left(s_{n}\right)\right]$. The vector $\mathbf{P}$ will sometimes be called the preference profile.

Consider now a set of job offers from hospitals to (acceptable) students, which, if the students each accept the best of the offers they have received (including the possibility of remaining unmatched), would result in an unstable outcome $x$. The fact that $x$ is unstable means that there is a hospital $h_{i}$ and a student $s_{j}$ who would both prefer to $x$ another outcome at which $s_{j}$ was employed by $h_{i}$. So these two agents have an incentive to try to locate each other, and we might expect to witness the kind of last-minute turmoil observed in the intern market prior to 1951 . Looking at the other side of the coin, we might expect that any voluntary system of organizing the market would experience similar turmoil if it produced unstable outcomes." Since the NIMP is a voluntary system that has maintained a high degree of orderly participation for many years, it is reasonable to

\footnotetext{
${ }^{15}$ For markets with side payments, the core defined by weak domination coincides with the core defined by strong domination, and in the market studied here, when $q_{i}=$ 1 for each hospital $h$, the two cores also coincide. However, in the more general case considered here, the core defined by weak domination is contained in the core defined by strong domination. See Roth and Postlewaite (1977) for a related discussion. For our purposes, the distinction will not be consequential, and the set of stable outcomes will henceforth be referred to simply as the core, and stable outcomes will also be called core outcomes, However, there are differences between the special case when all $q_{i}=1$ and the general case considered here that bear on this distinction (see Roth 19846).

16 A system that produces tinstable outcomes gives at least some agents the incentive to go outside the svstem to find one another and arrange their employment. Only in a system where participation is voluntary, however, can we expect to observe agents acting on these incentives.
} 
conjecture that it produces stable outcomes, that is, outcomes in the core of the market. The following theorem, which will be proved in Section $V$, supports this conjecture.

тнеовем 1: Let $\mathrm{P}$ be the vector of preferences (the rank-order lists) submitted by the students and hospitals. Then the NIMP algorithm produces an outcome in $\mathrm{C}(\mathrm{P})$.

When we consider in Section IIIB the incentives agents have to state their true preferences, we will examine from another viewpoint the question whether a stable outcome is achieved under the current organization of the market. First, however, we consider some results that concern the fact that different outcomes in the core differentially favor the two sides of the market. Specifically, theorem 2 states that, in a certain strong sense, the outcome produced by the NIMP algorithm is the best core outcome for all the hospitals and the worst for all the students. The following definitions will be used in stating the theorem.

For a given preference profile $\mathrm{P}$, a students, and a hospital $h_{i}$ will be called achievable for one another if there is some stable outcome at which $s_{j}$ is employed by $h_{i}$, that is, if there is an outcome $x$ in C(P) such that $x\left(s_{j}\right)=h_{i}$. For each $h_{i}$, let $p_{i}$ be the number of achievable students; that is, $p_{i}=\left\{s_{j} \mid s_{j}\right.$ is possible for $\left.h_{i}\right\} \mid$, and define $k_{i}$ by $k_{i}=\min \left\{q_{i}, p_{i}\right\}$. Thus $k_{i}$ equals the minimum of the number of positions offered by $h_{i}$ or the number of different students who could fill those positions at some stable outcome.

тнеове 2: Let $\mathrm{P}$ be the preference profile (i.e., the rank-order lists) submitted by the students and hospitals. Then the outcome produced by the NIMP algorithm has the property that each hospital $h_{i}$ is assigned its $k_{i}$ highest ranked achievable students, and each student $s_{j}$ is assigned his lowest ranked achievable alternative. ${ }^{17}$

Note that not only is there no trade-off between hospitals-they all simultaneously receive their best achievable students-but within a hospital there need be no trade-off between achievable students. The theorem implies, for example, that if a hospital $\boldsymbol{h}_{\boldsymbol{i}}$ with two positions $(q,=2)$ employs its first- and third-ranked student at one stable outcome and its second- and fourth-ranked student at another stable outcome, then at the outcome produced by the NIMP algorithm it is assigned its first- and second-ranked student. The theorem is proved in Section V.

Note that theorems 1 and 2 can both be stated as existence results. Theorem 1 states that the core of the market is nonempty, and theorem 2 states that (when the preference profile consists of rank

\footnotetext{
${ }^{17}$ For a student (or hospital) who is unmatched at some stable outcome, being unmatched will be the lowest-ranked achievable alternative.
} 
orderings-i.e., strict preferences) there is a core outcome that is best for all the hospitals and worst for all the students. These existence results were first stated by Gale and Shapley (1962), who were unaware of the NIMP procedure, which had then been in operation for 10 years. ${ }^{18}$ In order to prove these existence results, they developed an algorithm that is considerably simpler than the NIMP algorithm but turns out to be equivalent; that is, for a given preference profile of strict preferences, the two algorithms produce the same stable outcome. ${ }^{19}$ These existence results have recently been shown to hold in considerably more general kinds of labor markets (see Kelso and Crawford 1982; Roth 1984a, 1984d).

A corollary of the proof of theorem 2 is that there exists a stable outcome that is optimal for students in the same sense that the outcome described in theorem 2 is optimal for hospitals. That is, we can state the following:

Corollary 2.1: For any profile $P$ of strict preferences, there exists a stable outcome with the property that each student $s_{j}$ is assigned his highest-ranked achievable alternative.

\section{$B$. Incentives}

Let us now consider the incentives faced by agents when a centralized market mechanism is employed that requires as input agents' stated preferences over potential assignments. The adoption of any such mechanism creates a new game among the agents, who must decide what preferences to state. This point can perhaps be made most clearly by briefly considering the trial-run algorithm that was discarded in favor of the NIMP algorithm because of the incentive problems it was observed to cause.

Under the trial-run procedure (see Mullin and Stalnaker 1951), students submitted a rank ordering of hospitals to which they had applied, and hospitals submitted a ranking that divided students into five groups. The hospital gave a rank of 1 to its first-choice group of students, equal in size to the number of positions being offered; simi-

\footnotetext{
18 As a historical note, I am indebted to David Gale for telling me that he first became aware of the labor market for interns in 1976, when he was told of it by a physician who heard him speak on the "marriage problem." At that time, he sent a copy of Gale and Shapley (1962) to an administrator of the NIMP, which seems to have been the first time that anyone associated with the program became aware of the game-theoretic formulation of the problem and the results concerning optimal outcomes in the core.

19 Gale and Shapley (1962) assumed that all agents had strict preferences. The NIMP algorithm, since it requires its input to be rank orderings, requires all agents to state their preferences as if they ${ }^{1}$ were strict-i.e., no indifferences can be expressed. Theorem 1 and the existence of stable outcomes are unchanged when agents are indifferent between some alternatives, but we will see in Sec. IV that theorem 2 becomes an artifact.
} 
TABLE 1

\begin{tabular}{lllcccc}
\hline \hline & \multicolumn{6}{c}{ AGENT } \\
\cline { 2 - 7 } RANK & $s_{1}$ & $s_{2}$ & $s_{3}$ & $h_{1}$ & $h_{2}$ & $h_{3}$ \\
\hline 1 & $h_{1}$ & $h_{2}$ & $h_{3}$ & $s_{2}$ & $s_{1}$ & $s_{3}$ \\
2 & $h_{2}$ & $h_{3}$ & $h_{3}$ & $s_{3}$ & $s_{2}$ & $s_{2}$ \\
3 & $h_{3}$ & $h_{1}$ & $h_{2}$ & $s_{1}$ & $s_{3}$ & $s_{1}$ \\
\hline
\end{tabular}

larly it gave a rank of 2 to an equal-size group of second-choice students, ranked less desirable students 3 and 4, and ranked unacceptable students 5 . The matching algorithm proceeded in stages, or runs. At the first of these, called the $1: 1$ stage, students and hospitals were matched if they had each given the other a rank of 1 . The next stage was $a 1: 2$ stage, where remaining students and hospitals were matched if the student had ranked the hospital 1 and the hospital ranked the student 2 . Then followed a 2: 1 stage, a 2: 2 stage, a 1: 3 stage, and so forth.

The difficulty observed by the student representatives after the trial run was that a student who did not match with his first-choice hospital might find that, say, his second-choice hospital had no places left by the time the $2: 1$ stage rolled around, so that even if his second choice had ranked him a 1, he might end up assigned to a lower-choice hospital. In this case, the student would have done better to have submitted a different rank ordering. The following example, in which there are three students and three hospitals, each offering one position, will make this completely clear. The rank orderings given in table 1 correspond to the true preferences of the agents.

If the agents all submit their true rank orderings, the trial-run algorithm finds no matches at the $1: 1$ stage, and at the $1: 2$ stage it matches $s_{2}$ with $h_{2}$ and $s_{3}$ with $h_{1}$, so that $s_{1}$ is ultimately matched with $h_{3}$, his third choice." However, if $s_{1}$ had ranked his second choice $h_{2}$ first, he would have been matched with it (at the $1: 1$ stage). So $s_{1}$ has an incentive to misrepresent his preferences strategically when submitting his rank order."'

\footnotetext{
${ }^{20}$ Note that this outcome is not stable. With respect to the preferences of the players as given in table 1 , there are exactly two stable outcomes, at both of which $s_{1}$ is matched with $h_{2}$. So the hospital-optimal stable outcome $x$ is given by $x\left(s_{1}\right)=h_{2}, x\left(s_{2}\right)=h_{1}, x\left(s_{3}\right)$ $=h_{3}$, which gives every hospital its first-choice student, The student-optimal stable outcome $y$ is given by $y\left(s_{1}\right)=h_{2}, y\left(s_{2}\right)=h_{3}, y\left(s_{3}\right)=h_{1}$, which gives hospitals $h_{1}$ and $h_{3}$ their second-choice student.

${ }^{21}$ A very similar matching procedure, which exhibits precisely the same incentive problem, is currently employed by the Fulbright Senior Scholars Awards Program, which matches American scholars with foreign universities (see Council for International Exchange of Scholars 1984). I am indebted to Gene Gruver for pointing this out to me.
} 
The NIMP algorithm was introduced with the claim that it solved this problem (see Mullin and Stdlnaker 1952; Graettinger and Peranson 1981). Under the NIMP procedure, both students and hospitals submitted rank orderings. It was essentially claimed that the NIMP algorithm made it a dominant strategy for every agent to state his true preferences; that is, each agent could do no better than to submit a rank ordering corresponding to his true preferences," no matter what preferences were submitted by other agents. The following results demonstrate that this claim is not quite correct, but that the NIMP algorithm comes as close in a certain sense to fulfilling this claim as is possible for a procedure that produces a stable outcome.

Theorems 3-7 will be stated here without proofs, which can be found in Roth (1982a) (theorems 3-6) and Roth (1984b,1984c) (theorem 7). The first of these results is an impossibility theorem for all stable matching procedures, which are defined to be functions from preference profiles $\mathbf{P}$ to stable outcomes $x(\mathbf{P})$ in $\mathrm{C}(\mathrm{P})$.

тнеове 3: No stable matching procedure exists for which it is a dominant strategy for all agents to state their true preferences.

Since the NIMP is a stable matching procedure, this theorem implies that there are circumstances in which it gives some agents the incentive to submit a rank ordering different from their true preferences. Specifically, the proof of this theorem in Roth (1982a) implies that it is not a dominant strategy for students participating in the NIMP to state their true preferences. However, the following results show that the NIMP procedure offers some relief from the incentive problems present in the trial-run algorithm that it replaced."'

тнеове 4: The NIMP procedure gives no student any incentive to misrepresent his true first choice.

In particular, any student who submits a rank ordering whose first element differs from his true first choice could always do at least as well by submitting an otherwise identical rank ordering whose first element is his true first choice. The example considered above shows that the NIMP procedure contrasts in this respect with the trial-run algorithm.

\footnotetext{
22 Let $\mathrm{P}^{*}$ be some agent's true preference ordering, and let $\mathrm{P}$ be the rank ordering he submits, which is necessarily a strict ordering. If the true preferences $\mathrm{P}^{*}$ are also strict, then $\mathrm{P}$ corresponds to $\mathrm{P}^{*}$ if and only if $\mathrm{P}=\mathrm{P}^{*}$. If the true preferences $\mathrm{P}^{*}$ are not strict, then $\mathrm{P}$ corresponds to $\mathrm{P}^{*}$ if and only if the fact that one alternative is strictly preferred to another under $\mathrm{P}^{*}$ implies it is strictly preferred under $\mathrm{P}$. (So if $\mathrm{P}^{*}$ expresses indifference between two alternatives, either may be ranked higher under $\mathrm{P}$ corresponding to P*.)

${ }^{23}$ In Roth $(1982 a, 1984 b)$, theorems 4,5 , and 7 were stated in terms of a stable matching procedure that always yielded the optimal stable outcome for a given side of the market. From the point of view of incentives, any two such procedures are equivalent. Here, therefore, the theorems can be stated in terms of the N I M P procedure, which by theorems 1 and 2 yields the hospital-optimal stable outcome.
} 
Since students are each assigned to only one hospital, the model presented here is adequate for discussing their incentives, since their preferences are defined over hospitals and their strategies involve rank orderings of hospitals. However, in order to discuss adequately the incentives facing hospitals that have more than one position to fill, it would be necessary to specify their preferences over groups of students. A complete description of the general case would take us well beyond the scope of this paper. But for the simple case of hospitals with only one position to fill $\left(q_{i}=1\right)$, the model discussed here is complete enough to allow us to state the following.

тнеовем 5: The NIMP procedure makes it a dominant strategy for all hospitals with one position to state their true preferences.

The NIMP procedure thus avoids some of the simple opportunities for misrepresentation offered by the trial-run algorithm. No student can profit from misrepresenting his first choice, and in the simple case in which hospitals have only a single position to offer, it is a dominant strategy for hospitals to state their true preferences. ${ }^{24}$ The following result shows that, in a certain sense, the NIMP procedure does as well as possible in this regard; no stable procedure exists that does all this and that also never makes it profitable for a student to misrepresent his second choice (even in the simple case in which hospitals have only single positions).

тнеове 6: No stable matching procedure exists for which it is $a$ dominant strategy for all agents to state their true kth choice, for $k \neq 1$.

In view of the fact that the NIMP procedure does not make it a dominant strategy for students to state their true preferences, we must now reconsider what reason there is to believe that the NIMP procedure in practice yields a stable outcome (in terms of the true preferences of the agents). That is, theorem 1 states that, for any preference profile $\mathrm{P}$ of submitted rank-order lists, the NIMP procedure yields an outcome in $\mathrm{C}(\mathrm{P})$, that is, a stable outcome with respect to the stated preferences. But since some students may have an incentive to misrepresent their preferences, the stated preferences $\mathbf{P}$ may not coincide with the true preferences $\mathbf{P} *$. What reason, then, do we have to believe that the outcome produced will be stable with respect to the true preferences? To put it another way, how can we explain the empirical fact that the NIMP procedure has produced an orderly

\footnotetext{
24 Theorem 5 is included here to help illustrate the manner in which the NIMP procedure comes close to achieving its desired aim of giving neither students nor hospitals any incentive to misrepresent their preferences. However, it is shown in Roth (19846) that the NIMP procedure does not in general make it a dominant strategy for hospital programs having more than one position to state their true preferences, and that in fact no stable matching procedure exists that has this property for such hospital programs
} 
market since 1951 , in contrast to the turmoil associated with the instability characteristic of the earlier forms of market organization it replaced?

Two kinds of answers can be given to this, depending on how much information the agents possess. First, if agents have little information about the preferences of other agents, they will not in general be able to determine an "optimal" misrepresentation. Together with the fact that the literature distributed to students and hospitals with the forms for their rank-order lists continues to claim that it is optimal to submit true preferences, this may persuade them to submit their true preferences. If so, the resulting outcome would be stable.

However, there is at least anecdotal evidence that many students are not persuaded that it is optimal to submit their true preferences, and there is substantial information available to them about the historical preferences of hospitals and students (e.g., which hospitals are prestigious, and what kind of medical-school records their interns must typically have to get an appointment). We must therefore consider whether it is consistent to expect that a stable outcome will result from the NIMP procedure when agents are rational and well informed, that is, when stated preferences can be expected to differ from true preferences. The traditional formulation in game theory of how such agents behave is that their stated preferences (i.e., strategy choices) will constitute a Nash equilibrium, so that each agent's stated preference gets him the best match obtainable, given the stated preferences of the others. The following theorem states that it is consistent to expect, in this case also, that the NIMP procedure will result in a stable outcome.

тнеовм 7: There exist Nash equilibria $\mathbf{P}$ of submitted rank-order lists such that the outcome produced by the NIMP procedure is stable with respect not only to $\mathbf{P}$, but also to the true preferences $\mathbf{P *}$. That is, the NIMP outcome is contained in $\mathbf{C}\left(\mathbf{P}^{*}\right)$ as well as in $\mathbf{C}(\mathbf{P})$.

\section{Contemporary Issues}

We now turn to some contemporary issues that have been raised concerning the present operation of the National Resident Matching Program (NRMP). In a certain sense, each of these issues concerns the underlying demographics of the market.

When the NIMP algorithm was first employed, there were many more internships being offered than there were students to fill them, and consequently all core outcomes were rather favorable for students. By the mid-1970s, however, the inclusion of foreign medical school graduates in the matching program had succeeded in closing the gap between the number of applicants and positions offered, and 
outcomes in the core were no longer so favorable to students." It is thus not surprising that the question of whether the NIMP algorithm unfairly favors hospitals at the expense of students eventually became an issue. ${ }^{26}$ However, the following result shows that the conflict of interest between students as a group and hospitals as a group evidenced in theorem 2 is at least partly an artifact of the NIMP procedure's requirement that participants submit rank orders (i.e., strict preferences) even when they may be indifferent between some potential matches.

THEOREM 8: When preferences are not all strict, there may exist no two stable outcomes such that all hospitals prefer one and all students prefer the other.

Thus when preferences are not strict, it is not in general meaningful to speak of a procedure that favors hospitals over students. In the example used in the proof of this theorem, in Section VI, any stable procedure must favor some hospitals and students at the expense of other hospitals and students.

A nother issue that has been raised concerns the geographic distribution of interns and residents to hospitals. For example, Sudarshan and Zisook (1981) write:"

Williams and his colleagues correctly point out that a great deal of subtlety and structure in the present matching system are probably not appreciated by the casual observer. Nevertheless, an obvious answer to their question of why the present system and not its mirror image holds sway is apparent. The United States suffers a terrible problem of maldistribution of physicians, with urban areas being relatively over-

\footnotetext{
"Mullin and Stalnaker (1952) report that in the first year of operation of the NIMP procedure. 10,4 14 positions were offered through the program to 5.681 student participants, of whom 98 percent were assigned internships by the algorithm. (They furthes report that of these students, 84 percent received their highest-ranked choice and another 10 percent their second choice.) By 1976, Graettinger (1976) reports that 16,112 positions were offered through the program, compared to 16,728 student participants (of whom 11,735 were U.S. medical school graduates). In that year only 73 percent of the students (including 92 percent of the U.S. students) were matched by the algorithm. (Each year students and hospitals who are unmatched are able to seek one another out after the matching procedure has taken place.)

${ }^{26}$ See Williams, Werth, and Wolff (1981), who reach a conclusion resembling theorem 2 on the basis of some examples. By this time, Gale and Shapley's 1962 paper is sometimes referenced in the medical literature (see n. 18). not always correctly. However, a number of authors appeared to be aware of the equivalence of the NIMP algorithm and the Gale-Shapley algorithm (in at least some cases reaching this conclusion because of a belief that the two algorithms are the same). In Sec. VII, the difficulty of precisely tracing the history of ideas in the literature will be briefly discussed.

27 Sudarshan and Zisook (1981) wrote in response to Williams et al. (1981). They were aware of Gale and Shapley (1962), but believed it implied that only two stable outcomes exist, namely a hospital-optimal stable outcome and its "mirror-image" student-optimal outcome.
} 
served and inner-city and rural areas being relatively underserved. At present, although approximately 100 hospitals fill every residency position, there are over 100 hospitals that do not receive a single application. This maldistribution would only be worsened by the only rational alternative to the present matching program, the mirror-image program, which favors students. [P. 526]

The following theorem shows that, in fact, when all preferences are strict (so that hospital and student optimal stable outcomes exist), the selection of a particular stable outcome will affect only which students are assigned to which hospitals and will not have any effect on which hospital positions are filled and which students are matched. That is, the particular stable outcome selected will not have any influence on the geographic distribution of matched students.

theоrem 9: When all preferences are strict, the set of hospital positions filled is the same at every stable outcome, as is the set of students who are assigned positions.

This theorem is proved in Section VI.

The final issue to be considered here concerns the fact that increasing numbers of medical students marry other medical students and seek to be assigned positions in the same community. At present these couples have two options: they may enter the centralized matching process together and be matched by means of a special "couples algorithm," or they may elect to remain outside of the centralized process and negotiate directly with hospital programs. In recent years, increasing numbers of couples have adopted this second option, declined to participate in the match, and managed to arrange their own positions with hospitals."'

In the light of the preceding analysis, we should suspect that if couples and hospitals both find it profitable to make their arrangements outside of the matching program it must be that the couples algorithm produces outcomes that are unstable with respect to couples. This turns out to be the case. The couples algorithm used up until 1983 did not permit a couple to specify its preferences over pairs of positions. Instead, each couple submitted a rank-order list for each spouse and assigned one spouse priority in the match. Elias and Elias (1980) discuss some of the drawbacks of this couples algorithm and propose that it be replaced by one allowing each couple to submit a rank-order list expressing its preferences over pairs of positions. (In the 1983 match, couples were for the first time allowed to express

\footnotetext{
${ }^{28}$ Quite early, Checker (1973) attributed the declining rate of participation in the matching program partly to married couples. (Hospitals that negotiate directly with couples may still seek to fill their remaining positions through the matching program.)
} 
such preferences; see the NRMP Directory [1983].) The following result indicates, however, that even when couples are allowed to state their preferences more accurately, the problem of finding a stable outcome may still be intractable, since such an outcome need not exist.

тнеове 10: In a market in which some agents are couples, the set of stable outcomes may be empty.

The proof is contained in Section VI.

\section{The NIMP Algorithm and Proofs of Theorems 1 and 2}

The NIMP algorithm (see Stalnaker 1953; Darley 1959; NZRMP Directory 1979) works as follows. Each hospital program rank orders the students who have applied to it (marking " $X$ " any students who are unacceptable) and each student rank orders the hospital programs to which he has applied (similarly indicating any that are unacceptable). These lists are mailed to the central clearinghouse, where they are edited by removing from each hospital program's rank-order list any student who has marked that program as unacceptable and by removing from each student's list any hospital that has indicated he is unacceptable. (I am indebted to John S. Graettinger for explaining this initial editing.) The edited lists are thus rank orderings of acceptable alternatives.

These lists are entered into what may be thought of as a listprocessing algorithm consisting of a matching phase and a tentativeassignment-and-update phase. The first step of the matching phase (the 1: 1 step) checks to see if there are any students and hospital programs that are top ranked in one another's ranking. (If a hospital $h_{i}$ has a quota of $q_{i}$, then the $q_{i}$ highest students in its ranking are top ranked.) If no such matches are found, the matching phase proceeds to the 2: 1 step, at which the second-ranked hospital program on each student's ranking is compared with the top-ranked students on that hospital's ranking. At any step, when no matches are found the algorithm proceeds to the next step, so the generic $k: 1$ step of the matching phase seeks to find student-hospital pairs such that the student is top ranked on the hospital's ranking and the hospital is kth ranked by the student. At any step where such matches are found, the algorithm proceeds to the tentative-assignment-and-update phase.

When the algorithm enters the tentative-assignment-and-update phase from the $k: 1$ step of the matching phase, the $k: 1$ matches are tentatively made; that is, each student who is a top-ranked choice of his kth-choice hospital is tentatively assigned to that hospital. The rankings of the students and hospitals are then updated in the follow- 
ing way. Any hospital that a student $s$, ranks lower than his tentative assignment is deleted from his ranking (so the updated ranking of a student $s$, tentatively assigned to his kth choice now lists only his first $k$ choices), and student $s_{\text {, }}$ is deleted from the ranking of any hospital that was deleted from $s_{j}$ 's ranking (so the updated rankings of each hospital now include only those applicants who have not yet been tentatively assigned to a hospital they prefer). Note that if one of a hospital's top-ranked candidates is deleted from its ranking, then a lower-ranked choice moves into the top-ranked category, since the hospital's updated ranking has fewer students, but the same quota, as its original ranking. When the rankings have been updated in this way, the algorithm returns to the start of the matching phase, which examines the updated rankings for new matches. Any new tentative matches found in the matching phase replace prior tentative matches involving the same student. (N ote that new tentative matches can only improve a student's tentative assignment, since all lower-ranked hospitals have been deleted from his ranking.) The algorithm terminates when no new tentative matches are found, at which point tentative matches become final. That is, the algorithm matches students with the hospitals to which they are tentatively matched when the algorithm terminates. Any student or hospital position that was not tentatively matched during the algorithm is left unassigned and must make subsequent arrangements by negotiating directly with other unmatched students or hospitals. (See fig. 1 for a schematic of the algorithm.)

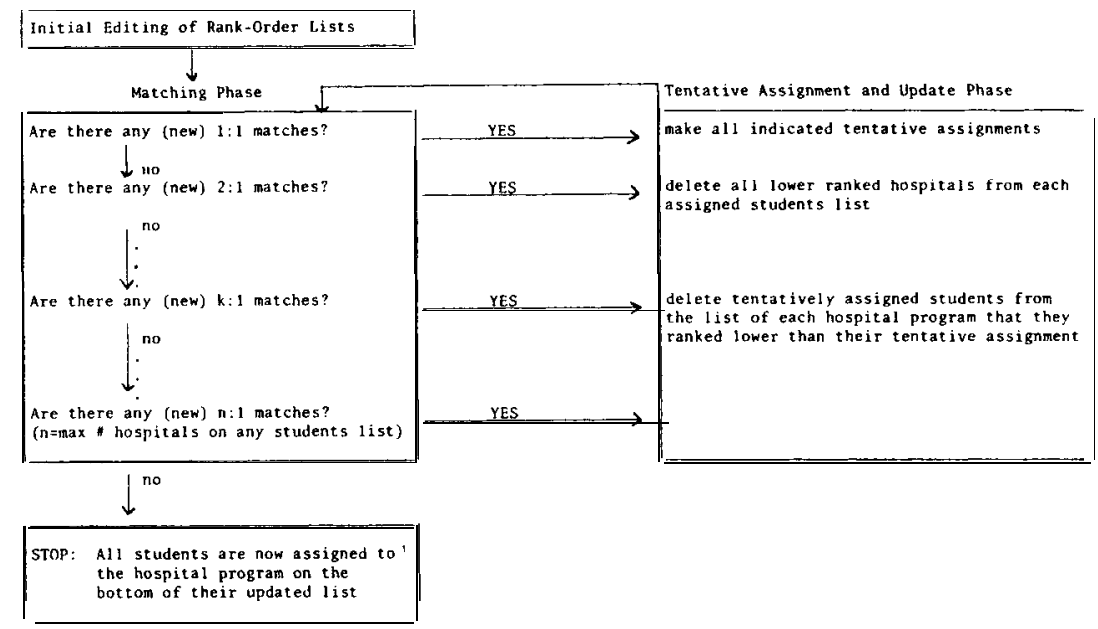

FIg. 1.-The NIMP algorithm 
The proofs of theorems 1 and 2 given below closely follow the treatment of Gale and Shapley (1962) and together amount to a formal proof that the NIMP algorithm and the,algorithm considered by Gale and Shapley are equivalent.

Proof of theorem 1: When the algorithm terminates, each hospital $h_{i}$ is matched with the top $q_{i}$ choices (i.e., the top-ranked choices) on its final updated rank-order list. (This follows, since the algorithm does not terminate while tentative $k: 1$ matches can still be found.) This assignment is stable, since any student $s$, whom some hospital $h_{r}$ originally ranked higher than one of its final assignees was deleted from $h_{i}$ 's ranking when $s_{j}$ was given a tentative assignment higher in his ranking than $h$. Hence the final assignment gives $s_{j}$ a position he ranked higher than he ranked $h_{i}$. So the final outcome is not unstable with respect to any such $h_{i}$ and $s_{j}$.

Proof of Theorem 2: To prove the first part of the theorem, it will be sufficient to show that no achievable student is ever deleted from a hospital program's rank-order list, so that the final assignment gives each hospital program its best achievable assignments. This can be seen by induction. Suppose that, 'up to the rth iteration of the algorithm, no student has been deleted from the ranking of a hospital for which he is achievable, and that on the $(r+1)$ st iteration student $s$, is tentatively matched with hospital $h_{i}$ and deleted from the ranking of hospital $h_{k}$. Then any assignment that matches $s_{j}$ with $h_{k}$ and assigns achievable matches to $h$, is unstable, since $s$, ranked $h_{i}$ higher than $h_{k}$ and $h_{i}$ ranked $s_{j}$ higher than at least one of its assignees. (This follows since $s$, was top ranked by $h$, at the end of the rth iteration, when no achievable students had yet been deleted from $h_{i}$ 's rank-order list.) So $s_{j}$ is not achievable for $h_{k}$.

The second part of the theorem is now straightforward, since any outcome y that some $s$, likes less than the hospital-optimal outcome $x$ is unstable if the hospital $x\left(s_{j}\right)$ is assigned some student at $\mathrm{y}$ whom it likes less than $s_{j}$.

Corollary 2.1 follows in a straightforward way by considering the NIMP algorithm with the roles of students and hospitals reversed, so that each student is treated as a hospital with one position to offer and each hospital is treated as a student with $q_{i}$ top-ranked choices.

\section{Proofs of Theorems 8, 9, and 10}

Proof оғтнатем 8: Consider the market in which there are three hospitals, $H=\left\{h_{1}, h_{2}, h_{3}\right\}$, each offering one position, and three students, $S=\left\{s_{1}, s_{2}\right.$, ss $\}$. Hospital $h_{1}$ is indifferent between $s_{1}$ and $s_{2}$, whom it prefers to $s_{3}$, that is, $s_{1} I\left(h_{1}\right) s_{2} \mathbf{P}\left(h_{1}\right) s_{3}$. Hospital $h_{2}$ strictly prefers $s_{1}$ to $s_{3}$ to $s_{2}$, while $h_{3}$ prefers $s_{2}$ to $s_{3}$ to $s_{1}$. The preferences of 
the students are given by $h_{1} \mathbf{P}\left(s_{1}\right) h_{2} \mathbf{P}\left(s_{1}\right) h_{3}, h_{1} \mathbf{P}\left(s_{2}\right) h_{3} \mathbf{P}\left(s_{2}\right) h_{2}$, and $h_{1} \mathbf{P}\left(s_{3}\right) h_{2} \mathbf{P}\left(s_{3}\right) h_{3}$. There are exactly two stable outcomes in this market, $x$ and $y$, given by $x\left(s_{1}\right)=h_{1}, x\left(s_{2}\right)=h_{3}, x\left(s_{3}\right)=h_{2}, x\left(h_{1}\right)=s_{1}, x\left(h_{2}\right)=s_{3}$, $x\left(h_{3}\right)=s_{2}$, and $y\left(s_{1}\right)=h_{2}, y\left(s_{2}\right)=h_{1}, y\left(s_{3}\right)=h_{3}, y\left(h_{1}\right)=s_{2}, y\left(h_{2}\right)=s_{1}$, $y\left(h_{3}\right)=s_{3}$. Hospital $h_{1}$ is indifferent between its assignment at $x$ and at $y$, while hospital $h_{2}$ and student $s_{2}$ prefer $y$ to $x$, and hospital $h_{3}$ and students $s_{1}$ and $s_{3}$ prefer $x$ toy. So each stable outcome is preferred to the other by some students and some hospitals.

P RoOF оғ т теовем 9: For any outcome $z$, let $\mathbf{P}(z)$ denote the set of hospital positions filled at $z$. (To make the definition precise, let the $q_{i}$ identical positions offered by hospital program $h_{i}$ be numbered, so that if $k$ of these positions are filled at $z$ they are taken to be the first $k$ positions.) Let $p(z)=|\mathbf{P}(z)|$ be the number of positions filled. Similarly let $Q(z)$ denote the set of students assigned to positions at outcome $z$, and let $q(z)$ denote their number (so $n-q[z]$ students are unmatched at $z$ ). Let $x$ be the hospital-optimal stable outcome, and let y be the student-optimal stable outcome; both exist since all preferences are strict. Then theorem 2 implies that $\mathbf{P}(\mathbf{x})$ contains $\mathbf{P}(\mathbf{z})$ for all stable outcomes $z$, and consequently $p(x) \geqslant \mathrm{p}(\mathrm{z})$. This latter inequality implies $q(x) \geqslant q(z)$ for all stable outcomes $z$, since every position is filled by exactly one student, that is, since $p(z)=q(z)$ for every outcome $z$. Theorem 2 also implies that $Q(x)$ is contained in $Q(z)$ for all stable outcomes $z$, so $q(x) \leqslant q(z)$. Hence $Q(x)=Q(z)$ for all stable $z$; that is, the set of students who are assigned positions is equal to $Q(x)$ at every stable outcome $z$. But $q(x)=q(z)$, and hence $p(x)=p(z)$ for every stable outcome $z$. Since $\mathbf{P}(x)$ contains $\mathbf{P}(\mathbf{z}), \mathbf{P}(\mathbf{z})=\mathbf{P}(\mathbf{x})$ for all stable $z$ : the set of hospital positions filled at any stable outcome $z$ is equal to $\mathbf{P}(x)$.

Proof of TheOREM 10: Consider the market with hospitals $H=\left\{h_{1}\right.$, $\left.h_{2}, h_{3}, h_{4}\right\}$, each of which offers exactly one position and each of which has strict preferences over students $S=\{1,2,3,4\}$ as given in table 2 . The students consist of two married couples, $\{1,2)$ and $(3,4)$. Each couple has strict preferences over ordered pairs of hospitals, as given in table 2 . Thus couple $\{1,2)$ have as their first choice that student 1 be matched with $h_{1}$ and student 2 with $h_{2}$, and have as their last choice that student 1 be matched with $h_{2}$ and student 2 with $h_{1}$. The 24 possible assignments of students to hospitals are listed in table 3 , along with the reason each such outcome is unstable. Thus outcome 1 , which assigns student i to hospital $h_{i}, i=1, \ldots, 4$, is unstable because both hospital $h_{2}$ and couple $(3,4)$ would prefer that student 4 be matched with $h_{2}$. (This follows since $h_{2}$ prefers student 4 to student 2 , and $(3,4)$ prefers $h_{3} h_{2}$ to $h_{3} h_{4}$.) Note that the emptiness of the set of stable outcomes here is not a "knife-edge" phenomenon. The example would be completely unchanged, for instance, if any preferences for $h_{2}$ that kept student 4 as the first choice were substituted. 
TABLE 2

Preferences of Hospitals and Couples

\begin{tabular}{|c|c|c|c|c|c|}
\hline \multicolumn{4}{|c|}{ Hospitals' Rank Orders } & \multicolumn{2}{|c|}{ Couples' Rank Orders } \\
\hline$\overline{h_{1}}$ & $h_{2}$ & $h_{3}$ & $\overline{h_{4}}$ & $\overline{\{1,2\}}$ & $\overline{\{3,4\}}$ \\
\hline $\begin{array}{l}4 \\
2 \\
1 \\
3\end{array}$ & $\begin{array}{l}4 \\
3 \\
2 \\
1\end{array}$ & $\begin{array}{l}2 \\
3 \\
1 \\
4\end{array}$ & $\begin{array}{l}2 \\
4 \\
1 \\
3\end{array}$ & $\begin{array}{l}h_{1} h_{2} \\
h_{4} h_{1} \\
h_{4} h_{3} \\
h_{4} h_{2} \\
h_{1} h_{4} \\
h_{1} h_{3} \\
h_{3} h_{4} \\
h_{3} h_{1} \\
h_{3} h_{2} \\
h_{2} h_{3} \\
h_{2} h_{4} \\
h_{2} h_{1}\end{array}$ & $\begin{array}{l}h_{4} h_{2} \\
h_{4} h_{3} \\
h_{4} h_{1} \\
h_{3} h_{1} \\
h_{3} h_{2} \\
h_{3} h_{4} \\
h_{2} h_{4} \\
h_{2} h_{1} \\
h_{2} h_{3} \\
h_{1} h_{2} \\
h_{1} h_{4} \\
h_{1} h_{3}\end{array}$ \\
\hline
\end{tabular}

TABLE 3

Every Outcome Is Unstable

\begin{tabular}{|c|c|c|c|c|c|}
\hline Outcome & $h_{1}$ & $h_{2}$ & $h_{3}$ & $h_{4}$ & Unstable with respect to \\
\hline 1 & 1 & 2 & 3 & 4 & 4. $h_{2}$ \\
\hline 2 & 1 & 2 & 4 & 3 & $4, h_{2}$ \\
\hline 3 & 1 & 3 & 2 & 4 & $2, h_{4}$ \\
\hline 4 & 1 & 3 & 4 & 2 & $4, h_{1}$ \\
\hline 5 & 1 & 4 & 2 & 3 & $2, h_{4}$ \\
\hline 6 & 1 & 4 & 3 & 2 & $4, h_{1}$ \\
\hline 7 & 2 & 1 & 3 & 4 & $4, h_{1}$ \\
\hline 8 & 2 & 1 & 4 & 3 & $4, h_{2}$ \\
\hline 9 & 2 & 3 & 1 & 4 & $2, h_{4}$ \\
\hline 10 & 2 & 3 & 4 & 1 & $4, h_{1}$ \\
\hline 11 & 2 & 4 & 1 & 3 & $2, h_{4}$ \\
\hline 12 & 2 & 4 & 3 & 1 & $4, h_{\mathrm{J}}$ \\
\hline 13 & 3 & 1 & 2 & 4 & $4, h_{2}$ \\
\hline 14 & 3 & 1 & 4 & 2 & $2, h_{3}$ \\
\hline 15 & 3 & 2 & 1 & 4 & $2, h_{4}$ \\
\hline 16 & 3 & 2 & 4 & 1 & $2, h_{3}$ \\
\hline 17 & 3 & 4 & 1 & 2 & $1, h_{1}$ \\
\hline 18 & 3 & 4 & 2 & 1 & $2, h_{1}$ \\
\hline 19 & 4 & 1 & 2 & 3 & $4, h_{2}$ \\
\hline 20 & 4 & 1 & 3 & 2 & $2, h_{3}$ \\
\hline 21 & 4 & 2 & 1 & 3 & $2, h_{4}$ \\
\hline 22 & 4 & 2 & 3 & 1 & $2, h_{3}$ \\
\hline 23 & 4 & 3 & 1 & 2 & $3, h_{3}$ \\
\hline 24 & 4 & 3 & 2 & 1 & $4, h_{4}$ \\
\hline
\end{tabular}




\section{Concluding Remarks}

The NIMP algorithm, which was adopted in 1951, produces the hospital-optimal outcome in the core of the market. It is therefore noteworthy that the core was not formally defined as an independent solution concept in game theory until 2 years later, in the work of Gillies (1953a, 19536) and Shapley (1953). The fact that the core was so structured in such markets as to contain optimal outcomes of this kind was not known until the work of Gale and Shapley (1962). The kinds of incentive questions that prompted the replacement of the 1950 trial-run algorithm were not commonly discussed in economics until at least 10 years later (see Green and Laffont [ 1979] for a survey), and the specific incentive properties of stable procedures in markets of this kind have been well understood only in the last few years. ${ }^{29}$ It is difficult to say precisely what was known about the NIMP algorithm when it was implemented, since the associated literature contains a number of correct assertions about its properties, alongside other assertions that are incorrect. However, it is clear that several ideas that subsequently became important in economic theory were earlier encountered in the course of organizing this medical labor market. ${ }^{30}$

A number of the contemporary problems arising in the medical labor market raise theoretical questions that seem likely to have more general significance. Perhaps the most topical of these is the problem of two-career couples referred to in the previous section. Since theorem 10 applies to quite general kinds of labor markets, some of the changes caused by increasing numbers of dual-career households in other labor markets may prove related to those discussed here.

29 There has been a considerable amount of recent independent work on incentives and other questions concerning matching problems. A nonconstructive proof of the existence of stable outcomes is given by Quinzii (1982) for a general class of games including both marriage markets and exchange economies with indivisibilities of the kind studied in Shapley and Scarf (1974). Roth and Postlewaite (1977). and Roth (19826). Theorem 3 has been independently obtained by Bergstrom and Manning (1982); a strengthening of theorem 5 to include coalitions has been discussed by Dubins and Freedman (198 1) and Ritz (1982), and Gale and Sotomayor ( 1983) make an observation analogous to theorem 9. Similar results are explored by Demange and Gale (1983) for a related model of matching, and I am indebted to David Gale for informing me that he and M. Sotomayor have obtained some results similar to those in Sec. IV. The structure of the set of stable outcomes in general markets of this kind is explored in Roth (1984a).

30 One of the goals expressed for the NIMP procedure was that it should achieve the same outcome as an orderly free market (see the brief historical review in Graettinger and Peranson 1981). Since it achieves an outcome in the core, there is a well-defined sense in which this goal is achieved. Partly because of the two-sided nature of labor markets, such a procedure is quite different from similarly motivated procedures for one-sided markets, as when students are to be assigned to dormitories (see Hylland and Zeckhauser 1979; Leonard 1983). 
A nother contemporary problem concerns adapting the matching procedure to the market for advanced residency positions, which are less homogeneous than positions for first-year graduates. ${ }^{31}$ And there remain open questions about the market 'described here and the forces prompting the adoption of this particular form of market organization. Specifically, the precise role that salary adjustments play in this market is still unclear, as are the market features that prevented salaries alone from clearing the market in an orderly way in the late $1940 \mathrm{~s} .{ }^{32}$

In conclusion, it bears repeating that the history of rule changes a market has undergone provides a valuable perspective from which to view the forces at work in the market. Game theory, which is the part of economic theory most explicitly concerned with the implications of different rules of organization, provides a natural theoretical framework to study these changes.

\section{References}

"Agreement on Internship Placement." J.Assoc. American Medical Colleges 20 (May 1945): 192-94.

“Appointment of' Interns." J.Assoc. American Medical Colleges 24 (May 1949): $174-75$.

Bergstrom, Theodore C., and Manning, Richard. "Can Courtship Be Cheatproof?" Mimeographed. Ann Arbor: Univ. Michigan, 1982.

Checker, Armand. "The National Intern and Resident Matching Program, 1966-72."J. Medical Educ. 48 (January 1973): 106-Y.

Council for International Exchange of Scholars. Fulbright Senior Scholars Awards Program, 1984185. Washington: Council for Internat. Exchange of Scholars, 1984.

Cut-ran, J. A. "Letter." J. Assoc. American Medical Schools 20 (January 1945): 37.

\footnotetext{
31 The labor market for advanced residencies is experiencing difficulties at present similar in origin to those experienced by the market for interns in the period covered here. Now, as then, the medical literature discussing the problem and what to do about it reflects a division of opinion between those who attribute the problems to flaws in the organization of the market and those who attribute them to flaws in the moral character of the participants. A not untypical proponent of the latter view, arguing against organizational changes in the market for psychiatric residencies, says, "Hopefully, the profession of medicine and its specialty of psychiatry will seek to avoid the mud of the marketplace" (Myers 1979, p. 110).

${ }^{32}$ However, it is not premature to speculate fairly specifically on these features. Recall that salary is not the dominant factor in determining students' preferences for hospital programs. Since students are making $a$ choice that has implications for their entire subsequent career as physicians, it is unsurprising that factors such as the reputation of the hospital as a training facility should play a critical role in determining their preferences. For a hospital to raise its reputation significantly would typically require expenses far beyond those associated with the salaries of residents. For many hospitals it must therefore be more feasible to fill positions that might otherwise go to residents with more senior physicians, for whom the hospital's educational role is not a concern.
} 
Darrach, William. "Letter." Bull. Assoc. American Medical Colleges 2 (January 1927): 68.

Darley, Ward. "The Seventh Annual Report of the National Intern Matching Program." J. Medical Educ. 34 (January 1959): 38-46.

Demange, Gabrielle, and Gale, David. "A Strategy-proof Allocation Mechanism for Two-sided Matching Markets." Mimeographed. Paper presented at the IMSSS-Economics workshop. Stanford, Calif.: Stanford Univ., 1983.

Dubins, L. E., and Freedman, D. A. "Machiavelli and the Gale-Shapley Algorithm." American Math. Monthly 88 (August/September 1981): 485-94.

Elias, Anthony David, and Elias, Ellen Roy. "Matching of Couples in the NRMP." New England J. Medicine 302 (June 19, 1980): 1425-26.

Fitz, Reginald. "Concerning Interns and Internships." J. Assoc. American Medical Colleges 14 (March 1939): 101-4.

Gale, David, and Shapley, Lloyd S. "College Admissions and the Stability of Marriage." American Math. Monthly 69 (January 1962): Y-15.

Gale, David, and Sotomayor, M. "Some Remarks on the Stable Matching Problem." Mimeographed. 1983.

Gillies, D. B. "Locations of Solutions." In Report of an Informal Conference on the Theory of N-Person Games, edited by Harold W. Kuhn. Princeton, N.J.: Princeton Univ., 1953. (a)

—_. "Some Theorems on N-Person Games." Ph.D. dissertation. Princeton Univ., 1953. (b)

Graettinger, John S. "Graduate Medical Education Viewed from the National Intern and Resident Matching Program." J. Medical Educ. 51 (September 1976): 703-15.

Graettinger, John S., and Peranson, Elliott. "The Matching Program." New England J. Medicine 304 (May 7, 1981): 1163-65.

Green, Jerry R., and Laffont, Jean-Jacques. Incentives in Public DecisionMaking. Amsterdam: North-Holland, 1979.

Hylland, Aanund, and Zeckhauser, Richard. "The Efficient Allocation of Individuals to Positions." J.P.E. 87 (April 1979): 293-314.

“The Internship Matching Plan.” J. Medical Educ. 27 (January 1952): 46.

"Internships." J. Assoc. American Medical Colleges 22 (January 1947): 45-46.

Kelso, Alexander S., Jr., and Crawford, Vincent P. "Job Matching, Coalition Formation, and Gross Substitutes." Econometrica 50 (November 1982): 1483-1504.

Leonard, Herman B. "Elicitation of Honest Preferences for the Assignment of Individuals to Positions." J.P.E. 91 (June 1983): 461-79.

"Modification of Cooperative Plan for Appointment of Interns." J. Assoc. American Medical Colleges 25, no. 6, pt. 1 (November 1950): 435-36.

Mullin, F. J. "A Proposal for Supplementing the Cooperative Plan for Appointment of Interns." J. Assoc. American Medical Colleges 25, no. 6, pt. 1 (November 1950): 437-42.

Mullin, F. J., and Stalnaker, John M. "The Matching Plan for Internship Appointment." J. Medical Educ. 26 (September 195 I): 34 1-45.

-. "The Matching Plan for Internship Placement: A Report of the First Year's Experience." J. Medical Educ. 27 (May 1952): 193-200.

Myers, J. Martin. "Reply.” J. Clinical Psychiatry 40 (February 1979): 110.

NIRMP Directory. Evanston, Ill.: National Resident Matching Program, 1979.

NRMP Directory. Evanston, 'Ill.: National Resident Matching Program, 1983.

Quinzii, Martine. "Core and Competitive Equilibria with Indivisibilities." Mimeographed. Paris: Ecole Polytechnique, Laboratoire d'Econometrie, 1982. 
"Report of the Committee on Internships of the Association of American Medical Colleges." J. Assoc. American Medical Colleges 21 (May 1946): 178.

Ritz, Zvi. "Incentives and Stability in Some Two-sided Economic and Social Models." Mimeographed. Urbana-Champaign: Univ. Illinois, Dept. Bus. Admin., 1982.

Roth, Alvin E. "The Economics of Matching: Stability and Incentives." Math. Operations Res. 7 (November 1982): 617-28. (a)

_. "Incentive Compatibility in a Market with Indivisible Goods." Econ. Letters 9, no. 2 (1982): 127-32. (b)

—_. "Conflict and Coincidence of Interest in Job Matching: Some New Results and Open Questions." Math. Operations Res. (1984), in press. (a)

. "Incentives in the College Admissions Problem and Related Twosided Markets." Working Paper no. 173. Univ. Pittsburgh, Dept. Econ., 1984. (b)

—. "Misrepresentation and Stability in the Marriage Problem." J. Econ. Theory (1984), in press. (c)

—_. "Stability and Polarization of Interests in Job Matching." Econometrica 52 (January 1984): 47-57. (d)

Roth, Alvin E., and Postlewaite, Andrew. "Weak versus Strong Domination in a Market with Indivisible Goods." J. Math. Econ. 4 (August 1977): 131-37.

Rutkow, Ira M., and Glasgow, Arthur H. "How Medical Students View the Application and Reviewing Procedure for Surgical Residency." J. Medical Educ. 53 (June 1978): 505-7.

Shapley, Lloyd S. "Open Questions." In Report of an Informal Conference on the Theory of N-Person Games, edited by Harold W. Kuhn. Princeton, N.J.: Princeton Univ., 1953.

Shapley, Lloyd S., and Scarf, Herbert. "On Cores and Indivisibility." J. Math. Econ. 1 (March 1974): 23-28.

Stalnaker, John M. "The Matching Program for Intern Placement: The Second Year of Operation." J. Medical Educ. 28 (November 1953): 13-19.

Sudarshan, Alex, and Zisook, Sidney. "National Resident Matching Program." New England J. Medicine 305 (August 27, 1981): 525-26.

Turner, Joseph. "Intern Selection: Wanted, an Orderly Plan." J. Assoc. American Medical Colleges 20 (January 1945): 26-32.

"Uniform Intern Placement Plan for 1949." J. Assoc. American Medical Colleges 24 (January 1949): 42.

Williams, Kevin Jon; Werth, Victoria P.; and Wolff, John A. "An Analysis of the Resident Match." New England J. Medicine 304 (May 7, 1981): 1165-66. 